Revista Brasileira de Meteorologia, v.25, n.3, 345 - 358, 2010

\title{
MUDANÇAS CLIMÁTICAS E RECURSOS HÍDRICOS NA BAHIA: VALIDAÇÃO DA SIMULAÇÃO DO CLIMA PRESENTE DO HADRM3P E COMPARAÇÃO COM OS CENÁRIOS
} A2 E B2 PARA 2070-2100

\author{
CLEMENTE AUGUSTO SOUZA TANAJURA ${ }^{1}$, FERNANDO GENZ ${ }^{1}$, \\ HERÁCLIO ALVES DE ARAÚJO²
}

${ }^{1}$ Universidade Federal da Bahia, Salvador, Ba, ${ }^{2}$ Instituto de Gestão das Águas e Clima (INGA), Salvador, Ba cast@ufba.br, rajendra.br@gmail.com, heraclio.araujo@gmail.com

Recebido Setembro 2009 - Aceito Fevereiro 2010

\begin{abstract}
RESUMO
Simulações do clima presente foram realizadas no Hadley Center, Reino Unido para o período de 1960 a 1990 com o modelo atmosférico regional HadRM3P aninhado no modelo global HadAM3. Ambos os modelos foram integrados com temperatura da superfície do mar (TSM) observada. Os resultados do HadRM3P, disponibilizados pelo CPTEC/INPE, foram investigados sobre o Estado da Bahia comparandoos com dados diários observados por uma rede de 29 estações meteorológicas do INMET. O modelo foi capaz de simular de forma acurada os principais padrões do ciclo sazonal de precipitação, temperatura e umidade relativa a $2 \mathrm{~m}$ em quase todo o Estado da Bahia. Entretanto, a magnitude da precipitação ao longo do litoral foi menor do que a observada, e o modelo não produziu nenhuma precipitação no semi-árido e oeste da Bahia durante os meses de junho-julho-agosto, impondo um cenário climático mais drástico que o observado. O HadRM3P foi também integrado aninhado no modelo acoplado oceano-terra-atmosfera HadCM3, recebendo a TSM prescrita produzida por esse modelo, para simular os cenários climáticos A2 e B2 do IPCC no período de 2070 a 2100. Essas simulações sobre o Estado da Bahia indicaram a redução da precipitação anual e o aumento da temperatura média do ar a $2 \mathrm{~m}$ em todo o Estado em relação à simulação do clima presente. $\mathrm{O}$ mesmo padrão de modificação da temperatura a $2 \mathrm{~m}$ e da precipitação foi produzido para os dois cenários, mas com maiores magnitudes para o A2. A maior redução de precipitação foi observada no litoral - cerca de 70\% - e o maior aumento de temperatura foi no noroeste e norte - cerca de $5^{\circ} \mathrm{C}$.

Palavras-chave: modelo regional HadRM3P, validação, mudanças climáticas no Estado da Bahia.
\end{abstract}

\begin{abstract}
CLIMATE CHANGE AND WATER RESOURCES IN BAHIA: VALIDATION OF THE HADRM3P PRESENT CLIMATE SIMULATION AND COMPARISON WITH THE

A2 AND B2 SCENARIOS FOR 2070-2100

Simulations of the present climate were performed in the Hadley Center, UK, for the period 1960-1990 with the regional atmospheric model HadRM3P nested in the global model HadAM3 integrated with observed sea surface temperature (SST). The results of this simulation, available at CPTEC/INPE, were investigated over the State of Bahia, Brazil, by comparing them against observed daily data from 29 INMET meteorological stations. The model was able to simulate the main patterns of the seasonal cycle of precipitation, mean $2 \mathrm{~m}$ temperature and humidity in the majority of the State of Bahia. However, the magnitude of precipitation along the shore was smaller than observation. Also, the model did not produce any precipitation in the semi-arid and western regions of Bahia during June-July-August. This imposed a more drastic climate scenario than observed. HadRM3P was also integrated nested in the coupled oceanland-atmosphere model HadCM3, with prescribed SST produced by this model, to simulate the IPCC A2 and B2 climate scenarios for the period 2070-2100. These simulations over the State of Bahia showed precipitation decrease and temperature increase with respect to the present climate simulation over all the State. The same patterns of anomalies were produced in the A2 and B2 scenarios, but higher magnitudes were obtained for the A2. The largest reduction in precipitation was produced along the shore - about $70 \%$ - and the highest increase in temperature was over the north and the northwest - about $5^{\circ} \mathrm{C}$.
\end{abstract}

Keywords: regional model HadRM3P, validation, climate change in the State of Bahia. 


\section{INTRODUÇÃO}

Desde a década de 1980, as evidências científicas são cada vez mais fortes acerca da possibilidade de mudança do clima global por efeito antrópico (Marengo, 2001). O Programa das Nações Unidas para o Meio Ambiente (PNUMA) e a Organização Meteorológica Mundial (OMM) estabeleceram em 1988 o Painel Intergovernamental de Mudanças Climáticas, cuja sigla em inglês é IPCC, materializando um esforço de pesquisa para avaliar o conhecimento científico sobre mudanças climáticas, estabelecer conexões entre a variabilidade climática e as atividades humanas, e elaborar cenários de mudanças climáticas até o final do século XXI. De acordo com o IPCC (2007), há projeção de aumento da temperatura média da superfície global entre $2^{\circ} \mathrm{C}$ e $4,5^{\circ} \mathrm{C}$ para o final do século XXI, em relação ao período de 1980 a 1999, com uma estimativa média de aumento de $3^{\circ} \mathrm{C}$.

Há evidências de que eventos extremos, tais como secas, enchentes, ondas de calor e de frio, furacões e tempestades têm sido mais freqüentes ou mais intensos, e têm produzido enormes perdas econômicas e de vidas em várias partes do planeta (e.g., Emanuel 2005). No Brasil, como exemplos de eventos extremos pode-se mencionar a ocorrência do furacão Catarina em março de 2004, a seca da Amazônia em 2005 e as secas no sul do país em 2004, 2005 e 2006 (Marengo e Valverde, 2007).

Considerando resultados da reanálise do National Centers for Environmental Prediction/National Center for Atmospheric Research (NCEP/NCAR) dos EUA, Chaves et al. (2008) identificaram um aumento de temperatura do ar a $2 \mathrm{~m}$ sobre quase todo o Brasil, para o período de 1976-2007 em relação a 1948-1975. Sobre o Nordeste do Brasil, esse aumento foi de cerca de 0,6oC, sendo que enfocando o período de 1992-2007 em relação a 1948-1975, o aumento de aproximadamente 1,2oC. Esse trabalho mostrou ainda forte indícios de que a variabilidade natural do clima associada as oscilações do El Niño não é a única responsável pelo aumento de temperatura na região Nordeste do Brasil, isto é, causas antrópicas devem ser também responsáveis.

O Centro de Previsão de Tempo e Estudos Climáticos do Instituto Nacional de Pesquisas Espaciais (CPTEC/INPE) e o Instituto de Astronomia, Geofísica e Ciências Atmosféricas da Universidade de São Paulo (IAG/USP) vêm trabalhando no desenvolvimento de cenários regionalizados para a América do Sul com modelos dinâmicos regionais e globais do sistema climático (Ambrizzi et al. 2007, Marengo et al. 2007). Os cenários investigados com mais detalhes foram o A2 e o B2 do IPCC. Esses cenários são descritos em detalhes em Nakicenovic e Swart (2000). O cenário A2 é pessimista em relação às emissões de gases de efeito estufa e projeta para 2100, por exemplo, uma emissão anual de aproximadamente $30 \mathrm{GtC}$ associada ao $\mathrm{CO}_{2}$, cerca de quatro vezes maior que a de 2005. Ele assume que regiões economicamente distintas serão consolidadas e que haverá pouca cooperação internacional na solução dos problemas globais. O crescimento econômico será muito heterogêneo entre as regiões e a grande diferença entre a renda média dos países industrializados e dos países em desenvolvimento hoje verificada não será reduzida. Haverá forte aumento populacional no planeta, atingindo 15 bilhões de habitantes em 2100. O cenário B2 é considerado otimista em relação às emissões de gases de efeito estufa e projeta para 2100, por exemplo, uma emissão anual menor que $14 \mathrm{GtC}$ associada ao CO2. Apesar de permancerem grandes discrepâncias de renda e mecanismos não muito eficientes de transferência de tecnologia, haverá ações que priorizam a educação em geral e a inovação tecnológica nas cidades, fazendo com que, por exemplo, os cidadãos dependam menos dos carros. Ele assume que haverá uma crescente preocupação com a sustentabilidade ambiental e social em todo o mundo, com governos descentralizados permitindo a influência da sociedade organizada e ambientalmente consciente. A população atingirá 10 bilhões de habitantes em 2100 .

A regionalização dos cenários A2 e B2 para a América do Sul e subregiões do Brasil foi abordada por Ambrizzi et al. 2007 e Marengo et al. 2007 com modelos regionais Eta, RegCM3 e HadRM3P com 50 km de resolução espacial horizontal, relativamente alta quando comparada às resoluções de 200 km comumente encontradas nos modelos globais para estudos climáticos. Os resultados médios dos modelos regionais empregados indicaram um aumento da temperatura da superfície em todas as estações do ano em toda a América do Sul, atingindo um máximo em regiões da Amazônia e do Nordeste durante o verão austral de aproximadamente $6^{\circ} \mathrm{C}$ e $3,5^{\circ} \mathrm{C}$ para os cenários A2 e B2 do IPCC. No Estado da Bahia e leste do Nordeste, o maior aumento médio de temperatura foi produzido em marçoabril-maio entre 2 e $3^{\circ} \mathrm{C}$ para o cenário $\mathrm{B} 2$ e entre 3 e $5^{\circ} \mathrm{C}$ para o A2. Em relação à precipitação, as projeções são de redução da chuva no Norte e Nordeste do Brasil (NEB), consistente com a maioria dos modelos globais do terceiro relatório do IPCC (2001), sendo a redução de chuva mais intensa no cenário pessimista A2 (Marengo et al., 2007). Tendo em vista que o NEB possui uma vasta região com clima semi-árido, alterações no seu período chuvoso podem agravar as condições para o desenvolvimento socio-econômico na região. Dessa maneira, conhecer o clima atual da região é importante para compreender e simular os diferentes cenários de mudança climática no NEB.

A variabilidade climática do Nordeste brasileiro (NEB) provém de efeitos combinados da ação de vários sistemas meteorológicos e das variações na intensidade e posição das circulações Hadley e Walker. Os ramos ascendentes dessas circulações sobre a Amazônia e a Zona de Convergência Intertropical (ZCIT) produzem ramos descendentes sobre o NEB e adjacências e sobre a Alta Subtropical do Atlântico Sul (Nobre e Molin, 1988). Quando presente, o movimento descendente sobre 
o NEB impede a formação de nuvens e precipitação, e provoca um grande contraste climático com a Amazônia e o leste do NEB na mesma faixa de latitudes.

Na faixa litorânea do NEB os totais anuais de precipitação excedem $1000 \mathrm{~mm}$. Para oeste, há um forte decréscimo da precipitação anual, com valores entre $400 \mathrm{~mm}$ e $800 \mathrm{~mm}$ no semi-árido (Kousky e Chu, 1978). Em áreas isoladas do semi-ário encontram-se valores de precipitação anual acima de $1000 \mathrm{~mm}$ associados com a formação rochosa da Chapada Diamantina. A oeste do semi-árido, se aproximando da região Amazônica, a precipitação anual volta a crescer alcançando valores acima de 1000 mm (Chaves 1999, pág. 29). No setor norte do NEB a precipitação anual atinge valores acima de $1100 \mathrm{~mm}$. Essa precipitação se concentra entre janeiro e maio, com período mais chuvoso de fevereiro a abril associado ao posicionamento mais ao sul da ZCIT.

No sul do Nordeste brasileiro, mais especificamente no Estado da Bahia, atuam sistemas meteorológicos que são responsáveis por precipitação, como a Zona de Convergência do Atlântico Sul (ZCAS), o vórtice ciclônico de altos níveis (VCAN), brisas terrestres, ondas de leste e sistemas frontais ou seus vestígios. A atuação desses sistemas determina períodos chuvosos bem definidos nas sub-regiões do Estado (Nobre e Molion 1988; Chaves 1999; Chaves e Cavalcanti 2001; Molion e Bernardo 2002).

O principal período chuvoso sobre o extremo sul e o semi-árido do Estado da Bahia, ocorre nos meses de novembro a janeiro, com máximo climatológico em dezembro (Kousky e Chu, 1978; Rao e Hada, 1990). A precipitação nesse período está associada à penetração de sistemas frontais ou seus vestígios (Kousky, 1979). A precipitação é modulada, principalmente, pela variabilidade da precipitação da Amazônia, pela posição da ZCAS, pela posição dos VCANs, pelas anomalias da temperatura da superfície do mar e pela variabilidade da alta subtropical do Atlântico Sul (Nogles-Paegle e Mo, 1997; Chaves e Cavalcanti, 2001; Chaves e Nobre, 2004).

Na parte leste do NEB, incluindo praticamente todo o litoral da Bahia, o principal período chuvoso ocorre nos meses de abril a junho. Este período chuvoso é em grande parte explicado pela interação de circulação de brisa terrestre com os ventos alísios predominantes de leste e sudeste. A interação entre o sistema de brisa local e os alísios impõe um pico de precipitação noturno (Kousky, 1980). As chuvas no litoral são ainda explicadas pela modulação dos alísios e da Alta Subtropical, pelos vestígios de sistemas frontais e pela posição dos VCANs. Na região central dos VCANs há na verdade movimento descendente do ar e ausência de nuvens e precipitação, mas na sua periferia há movimento ascendente que favorece a convecção (Kousky, 1979; Rao et al., 1993). De junho a agosto, as chuvas no leste do NEB são freqüentemente produzidas por perturbações ondulatórias dos ventos alísios. Essas perturbações, comumente chamadas de ondas de leste ou distúrbios ondulatórios de leste, são provocadas pela interação de ventos de sul - associados com sistemas frontais - com os alísios (Yamazaki e Rao, 1977).

A precipitação no NEB é também fortemente influenciada por variabilidade interanual, particularmente pelo El Niño/ Oscilação Sul (ENOS) (e.g., Kousky e Ropelewski, 1989) e pelo dipolo do Atlântico (e.g., Souza e Nobre, 1998). Particularmente, o semi-árido do NEB é uma região bastante vulnerável à essa variabilidade, pois se as chuvas no período chuvoso são fracas, há um prolongamento do período de estiagem com fortes secas e grande impacto na população, que muitas vezes depende de lavoura de subsistência. Quando se consideram cenários de mudanças climáticas, nos quais estima-se que haverá diminuição da precipitação anual e redução do período chuvoso no NEB, cria-se uma importante demanda para o estudo detalhado desses cenários e de seus impactos, visando mitigação e adaptação a essas condições (Ambrizzi et al. 2007, Marengo et al. 2007).

Um esforço de análise regional dos cenários de mudança climática sobre o Estado da Bahia, em parceria com o CPTEC/ INPE, vem sendo realizado através do projeto de pesquisa "Mudanças Climáticas e Recursos Hídricos na Bahia" financiado pelo Conselho Nacional de Pesquisa e Desenvolvimento Tecnológico (CNPq). O objetivo principal desse projeto é a simulação e análise das vazões produzidas pelo modelo hidrológico MGB-IPH (Collischonn e Tucci, 2001) alimentado com dados de simulações do modelo regional da atmosfera HadRM3P - do Hadley Centre, UK Meteorological Office, da Grã-Bretanha - para o clima presente e para os cenários futuros A2 e B2 do IPCC. O presente trabalho corresponde ao término da primeira etapa do projeto. Ele contempla a validação da simulação do clima presente (1960-1990) produzido pelo HadRM3P sobre o Estado da Bahia - usando dados observados in situ da rede de observações do Instituto Nacional de Meterologia (INMET) - e a comparação dos campos meteorológicos de superfície produzidos pelo HadRM3P sob os cenários A2 e B2 do IPCC do clima futuro (2070-2100) com os do clima presente.

Os detalhes sobre as simulações do clima presente e futuro e a metodologia para validação da simulação do clima presente estão apresentados na seção 2 . A seção 3 contém os resultados da validação e a comparação das simulações dos cenários de clima futuro com o presente. A seção 4 apresenta um resumo dos resultado e as conclusões.

\section{METODOLOGIA}

\subsection{Modelo Climático}

As simulações do clima presente foram produzidas pelo modelo regional da atmosfera HadRM3P para o período 
de janeiro de 1960 a dezembro de 1990 . O domínio do modelo regional foi de aproximadamente $95^{\circ} \mathrm{W}-20^{\circ} \mathrm{W}, 40^{\circ} \mathrm{S}-10^{\circ} \mathrm{N}$. O modelo regional foi integrado com resolução horizontal de 50 km, 19 níveis verticais da superfície até $30 \mathrm{~km}$ de altura e 4 níveis no solo. Ele foi aninhado no modelo global atmosférico HadAM3 configurado com 19 níveis na vertical e uma resolução de $2,5^{\circ}$ de latitude por $3,75^{\circ}$ de longitude, equivalente a uma resolução de 417 km x 278 km no equador, e 295 km x 278 km a $45^{\circ}$ de latitude. Ambos os modelos regional e global para o clima presente foram forçados com temperatura da superfície do mar (TSM) observadas com 1o de resolução espacial.

O modelo global HadAM3 é o componente atmosférico do modelo global amtosfera-terra-oceano-gelo HadCM3, que foi utilizado para produzir os cenários A2 e B2 do IPCC entre 2070 e 2100. A mesma configuração de seu componente atmosférico empregada para a simulação do clima presente foi usada para as integrações do A2 e B2, exceto pela inclusão de diferentes concentrações de gases de efeito estufa. O componente oceânico do HadCM3 é um modelo com coordenadas verticais z baseado no modelo de Brian e Cox. Ele possui mistura horizontal de traçadores e esquema de mistura vertical próximo à superfície. O fluxo de mometum vertical é modelado de acordo com o esquema da teoria-K. Mais detalhes sobre o modelo oceânico podem ser encontrados em Johns et al. (2003). Para os experimentos dos cenários A2 e B2 o modelo foi configurado com 20 níveis verticais e resolução horizontal de $1,25^{\circ} \times 1,25^{\circ}$, o suficiente para resolver alguns detalhes da estrutura das correntes oceânicas.

O HadAM3 permite a emissão, transporte e oxidação de compostos de enxofre, e com isso modela os efeitos diretos e indiretos das forçantes de sulfatos no clima. Os efeitos radiativos dos principais gases de efeito estufa são representados explicitamente, além de incluir uma parametrização dos efeitos dos aerossóis no balanço radioativo. O esquema de processos de superfície inclui a representação de ponto de congelamento e derretimento da umidade do solo, assim como de processos de escoamento superficial e profundo no solo. Mais informações sobre o modelo HadAM3 podem ser obtidas em Pope et al. (2000).

Cabe mencionar que a variabilidade do modelo HadAM3 integrado com TSM observada prescrita de 1960 a 1990 não é a mesma caso ele tivesse sido integrado acoplado a um modelo oceânico. Entretanto, a simulação com TSM prescrita pode ser considerada como a de um modelo acoplado que tivesse um modelo oceânico perfeito, isto é, um modelo que produzisse exatamente a TSM observada. O aninhamento do HadRM3P nessa simulação do HadAM3 com TSM observada visa produzir a melhor representação possivel do clima presente por esse modelo. Para o clima futuro, não é possível prescrever a TSM, pois ela depende intrinsicamente das condições atmosféricas do clima futuro, incluindo as novas concentrações de gases de efeito estufa. Por isso, o HadRM3P foi aninhado nas saídas do modelo acoplado oceano-atmosfera HadCM3 nas simulações dos cenários de clima futuro de 2070 a 2100. A TSM oferecida para o HadRM3P em seu domínio regional na simulação do clima futuro foi a TSM produzida pelo modelo acoplado de maneira que o cenário regional é regido de forma consistente pelo modelo acoplado e pela dinâmica interna do modelo regional.

Todas as integrações do HadRM3P foram realizadas no prório Hadley Center. Mais referências sobre os modelos HadRM3P e HadAM3 podem ser encontradas no site http:// precis.metoffice.com/index.html, em PRECIS (2002) ou em Ambrizzi et al. (2007).

Os dados diários de temperatura média do ar a $2 \mathrm{~m}$, umidade relativa do ar a $2 \mathrm{~m}$, radiação de onda longa, radiação de onda curta, ventos zonal e meridional, pressão reduzida ao nível do mar e precipitação do HadRM3P para a simulação do clima presente e para os cenários A2 e B2 foram gentilmente disponibilizados pelo Dr. José Marengo e pelo Sr. Daniel Santos do CPTEC/INPE. Esses dados foram manipulados pelos autores do presente trabalho para transformação de formato grib para formato binário com acesso direto, para consolidação da climatologia e para comparação com os dados observados nos pontos de observação.

\subsection{Dados Observados}

Os dados observados in situ usados nesse trabalho foram coletados por uma rede de 29 estações meteorológicas do INMET em operação no Estado da Bahia no período de 1960 a 1990. A Figura 1 mostra a localização das estações, e a Tabela

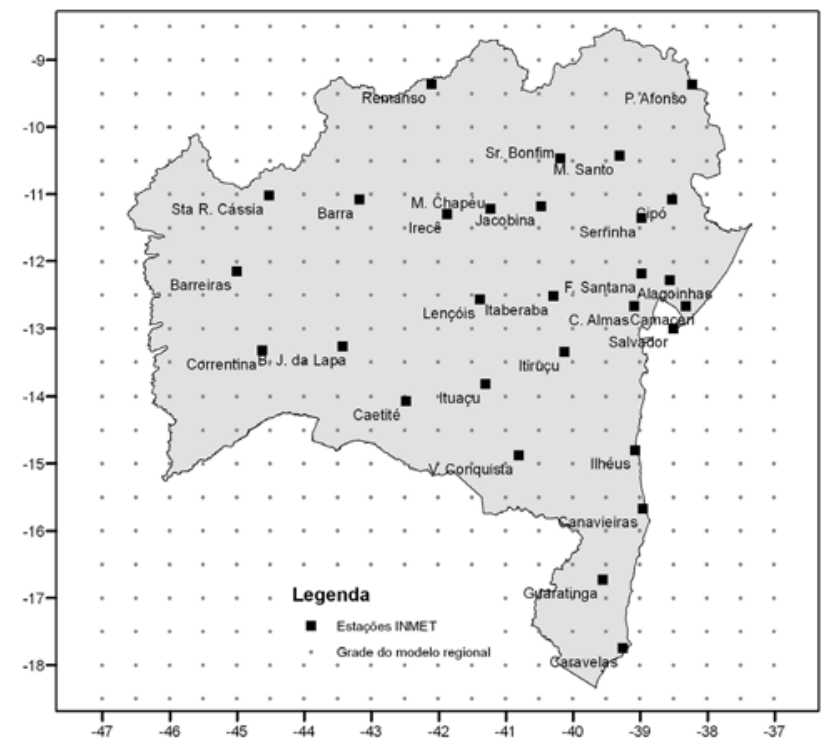

Figura 1 - Localização das estações meteorológicas do INMET no Estado da Bahia. 
1 apresenta algumas informações cadastrais. Com os dados diários dessas estações, foram calculadas médias mensais ao longo dos 30 anos, médias sazonais e a média anual. As médias anuais da temperatura do ar a $2 \mathrm{~m}$, umidade relativa do ar a $2 \mathrm{~m}$, pressão de superfície e precipitação para as 29 estações estão apresentadas na Tabela 2.

Com os dados in situ, foi realizada uma interpolação bi-linear para produzir campos de precipitação que possam ser usados na comparação com a simulação do clima presente.

\subsection{Definição de Erros do Modelo}

As variáveis do modelo escolhidas para a validação são aquelas que alimentarão na próxima etapa do projeto um modelo hidrológico de simulação do escoamento em bacias hidrográficas, a saber: (i) temperatura do ar a 2 m; (ii) umidade relativa do ar a 2 m; (iii) pressão de superfície; (iv) intensidade do vento; e (v) precipitação.

O valor diário da variável do modelo produzida pela simulação do clima presente de 1960 a 1990 ao longo dos 30 anos, foi inicialmente interpolado bilinearmente para o ponto de cada estação. Depois, os valores diários da simulação e da observação para cada ponto foram acumulados em valores mensais. Com esses valores mensais obtidos cada mês ao longo período de 1960 a 1990, foi então calculada a raiz quadrada do erro quadrático médio (EQM) para cada mês e o erro absoluto médio (EAM) para cada estação. O EQM é definido por:

$$
E Q M=\sqrt{\frac{1}{N} \sum_{n=1}^{N}\left(X m_{n}-X o_{n}\right)^{2}}
$$

onde $X m_{n}$ é o valor mensal da variável do modelo na estação n; $X o_{n}$ é o valor mensal da variável observada na estação $n ; N=29$.

O EAM é definido para cada estação $n$ por:

$$
E A M_{n}=\overline{\left(X m_{n}-X o_{n}\right)}
$$

e a barra representa a média no tempo considerando todos os meses ao longo dos 30 anos considerados, na verdade, de janeiro de 1960 a novembro de 1990 correspondendo a 372 meses.

Tabela 1 - Estações meteorológicas no estado da Bahia.

\begin{tabular}{clcccc}
\hline$n$ & Localidade & Código & Longitude & Latitude & Altitude $(m)$ \\
\hline 1 & Itiruçu (Jaguaquara) & 83295 & $-40,120$ & $-13,350$ & 756 \\
2 & Ituaçu & 83292 & $-41,300$ & $-13,820$ & 531 \\
3 & Jacobina & 83186 & $-40,470$ & $-11,180$ & 485 \\
4 & Lençóis & 83242 & $-41,380$ & $-12,570$ & 439 \\
5 & Monte Santo & 83090 & $-39,300$ & $-10,430$ & 465 \\
6 & Morro do Chapéu & 83184 & $-41,220$ & $-11,220$ & 1003 \\
7 & Paulo Afonso & 82986 & $-38,220$ & $-9,370$ & 253 \\
8 & Remanso & 82979 & $-42,100$ & $-9,360$ & 401 \\
9 & Salvador & 83229 & $-38,500$ & $-13,000$ & 51 \\
10 & Senhor do Bonfim & 83088 & $-40,180$ & $-10,470$ & 558 \\
11 & Serrinha & 83190 & $-38,970$ & $-11,360$ & 360 \\
12 & Santa Rita de Cássia & 83076 & $-44,520$ & $-11,020$ & 450 \\
13 & Vitória da Conquista & 83344 & $-40,800$ & $-14,880$ & 875 \\
14 & Alagoinhas & 83249 & $-38,550$ & $-12,280$ & 131 \\
15 & Barra & 83179 & $-43,170$ & $-11,080$ & 402 \\
16 & Barreiras & 83236 & $-45,000$ & $-12,150$ & 439 \\
17 & Bom Jesus da Lapa & 83288 & $-43,420$ & $-13,270$ & 437 \\
18 & Caetité & 83339 & $-42,480$ & $-14,070$ & 883 \\
19 & Camaçari & 83226 & $-38,317$ & $-12,667$ & 48 \\
20 & Canavieiras & 83398 & $-38,950$ & $-15,670$ & 4 \\
21 & Caravelas & 83498 & $-39,250$ & $-17,750$ & 3 \\
22 & Cipó & 83192 & $-38,520$ & $-11,080$ & 145 \\
23 & Correntina & 83286 & $-44,620$ & $-13,330$ & 550 \\
24 & Cruz das Almas & 83222 & $-39,080$ & $-12,670$ & 226 \\
25 & Feira de Santana & 83221 & $-38,970$ & $-12,180$ & 231 \\
26 & Guaratinga & 83446 & $-39,550$ & $-16,730$ & 195 \\
27 & Ilhéus & 83348 & $-39,067$ & $-14,800$ & 60 \\
28 & Irecê & 83182 & $-41,870$ & $-11,300$ & 747 \\
29 & Itaberaba & 82244 & $-40,283$ & $-12,520$ & 250 \\
\hline & & & & &
\end{tabular}




\section{RESULTADOS}

\subsection{Validação do Modelo Climático}

A comparação da precipitação climatológica anual produzida pelo HadRM3P com as observações está apresentada na Figura 2. O modelo produz um padrão de distribuição próximo do observado com maior precipitação em toda a faixa litorânea e no oeste do Estado, e com menor precipitação no nordeste. Entretanto, os valores simulados são inferiores aos observados na maior parte do Estado. Na faixa litorânea, o modelo produz entre 900 e $1500 \mathrm{~mm}$, enquanto as observações variam entre 1200 a $1800 \mathrm{~mm}$. No extremo oeste o modelo produz valores entre 700 e 1000 mm e as observações estão entre 900 a $1500 \mathrm{~mm}$. No nordeste do estado, na região $42^{\circ} \mathrm{W}-38^{\circ} \mathrm{W}$, $13^{\circ} \mathrm{S}-9^{\circ} \mathrm{S}$, o modelo simula valores abaixo de $500 \mathrm{~mm}$ e as observações apresentam

A comparação da precipitação climatológica sazonal produzida pelo HadRM3P com as observações também foi feita, e se concentrou nos meses de dezembro-janeiro-fevereiro (DJF), março-abril-maio (MAM), junho-julho-agosto (JJA) e setembrooutubro-novembro (SON), como apresenta as Figuras 3 e 4.
Em DJF, Figuras 3a e 3b, o máximo de precipitação está no oeste do Estado associado com o pico de precipitação na região sul da Amazônia, com a ZCAS e com vestígios de frentes frias que penetram em baixas latitudes. O modelo produz um valor máximo no oeste do Estado de aproximadamente 500 $\mathrm{mm}$, um pouco menor que o verificado na climatologia que apresenta valores de até $700 \mathrm{~mm}$. O mínimo de precipitação entre 100 e $200 \mathrm{~mm}$ produzido pelo modelo no nordeste do Estado e adjacências está também presente nas observações. O modelo apresenta, portanto, um bom padrão de distribuição e de magnitude da precipitação na região, incluindo detalhes como o máximo local no extremo sul da Bahia. Em MAM, Figuras 3c e 3d, o modelo produz o máximo de precipitação - acima de 400 mm - ao longo do litoral em concordância com as observações. Com marcante gradiente, a precipitação cai no centro do Estado onde o modelo e as observações chegam a valores mínimos entre $100 \mathrm{~mm}$ e $200 \mathrm{~mm}$. Na região da Chapada Diamantina e parte do extremo oeste da Bahia, as precipitações do modelo são menores que as observadas em cerca de $100 \mathrm{~mm}$.

Em JJA, Figuras 4a e 4d, período de ausência ou quase ausência de chuvas no oeste e em grande parte do semi-árido do Estado, o modelo não produz nenhuma precipitação nessas

Tabela 2 - Valores anuais climatológicos médios no Estado da Bahia no período de 1961 a 1990.

\begin{tabular}{|c|c|c|c|c|c|}
\hline & \multirow[t]{2}{*}{ Temperatura $\left[{ }^{\circ} \mathrm{C}\right]$} & \multirow[t]{2}{*}{ Umidade [\%] } & \multirow[t]{2}{*}{ Pressão atm $[\mathrm{hPa}]$} & \multicolumn{2}{|c|}{ Precipitação $[\mathrm{mm}]$} \\
\hline & & & & mensal & anual \\
\hline Média & 23,7 & 72,7 & 965 & 89,0 & 1068 \\
\hline Máxima & 26,4 & 83,2 & 1015 & 174,9 & 2099 \\
\hline Mínima & 19,7 & 60,1 & 900 & 48,6 & 583 \\
\hline
\end{tabular}
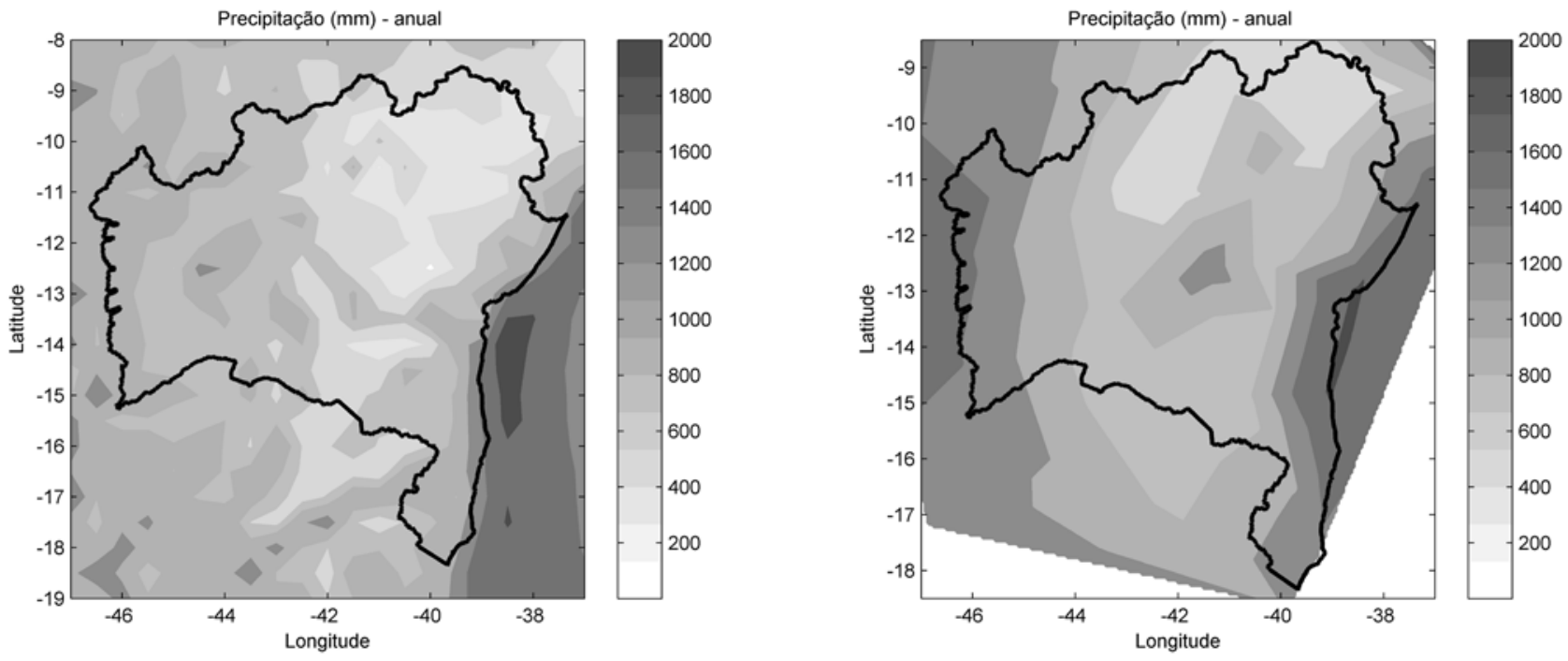

Figura 2 - Precipitação climatológica anual (mm) de acordo com (a) o HadRM3P e (b) dados observados do INMET. 
regiões, apesar das observações registrarem valores de até 25 mm. No litoral, o modelo produz mais chuva, com máximos entre 100 e 300 mm, mas abaixo do observado. Entre o litoral e a Chapada Diamantina, o modelo não consegue reproduzir a precipitação observada. Em SON, Figuras 4c e 4d, o modelo produz um mínimo no nordeste do Estado em torno de $25 \mathrm{~mm}$, menor do que a climatologia, a qual apresenta valores entre 100 e 200 mm. Os máximos no extremo sul e extremo oeste da Bahia produzidos pelo modelo são verificados nas observações.

Portanto, através de uma comparação visual, pode-se afirmar que em geral o modelo reproduz de forma acurada o padrão do ciclo sazonal médio da precipitação nas diversas sub-regiões do Estado da Bahia, as quais possuem diferentes comportamentos climatológicos. Entretanto, ele subestima a magnitude principalmente na região entre o litoral e a Chapada Diamantina em JJA e SON.

O mesmo procedimento usado para avaliar a precipitação climatológica anual e sazonal foi empregado para a temperatura média do ar a 2m, umidade relativa a $2 \mathrm{~m}$, pressão de superfície e intensidade do vento (não mostrado). De modo geral, o modelo capturou os principais padrões de distribuição de temperatura em todas as estações do ano. Entretanto, em DJF e MAM o modelo subestimou em cerca de $2^{\circ} \mathrm{C}$ a temperatura no oeste da Bahia e em cerca $1^{\circ} \mathrm{C}$ no extremo norte e no Vale do Rio São Francisco. Em JJA e SON, o modelo inverteu seu viés e produziu temperaturas de 1 a $30 \mathrm{C}$ maiores do que as observadas
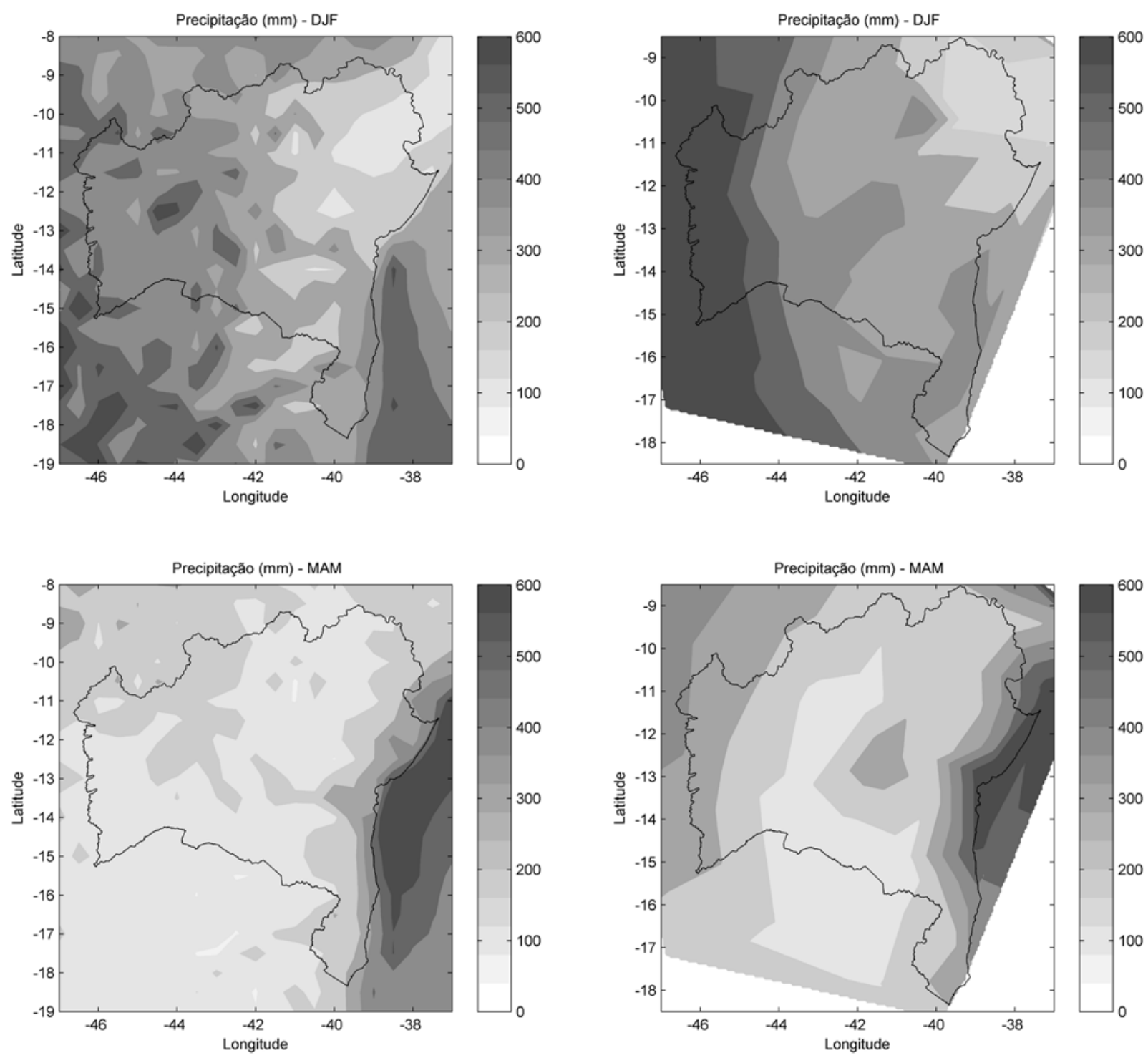

Figura 3 - Precipitação sazonal climatológica (mm) de acordo com o HadRM3P (coluna da esquerda) e dados observados do INMET (coluna da direita) para os meses de dezembro-janeiro-fevereiro em (a) e (b); e março-abril-maio em (c) e (d). 
nessas regiões. As diferenças nos campos de precipitação e temperatura têm reflexos na umidade relativa que não foi simulada pelo modelo. No oeste da Bahia e no Vale do Rio São Francisco, a umidade relativa foi substancialmente subestimada, principalmente em JJA e SON.

Para oferecer uma avaliação objetiva do modelo em relação às obsevações, o EQM e o EAM são discutidos. O EQM possui forte variabilidade interanual e atinge $250 \mathrm{~mm}$ em duas ocasiões ao longo dos 30 anos de simulação (não apresentado). Para a temperatura do ar em $2 \mathrm{~m}$, umidade relativa do ar em $2 \mathrm{~m}$, pressão de superfície e intensidade dos ventos, os erros máximos mensais em toda a série temporal foram, respectivamente, $2,5^{\circ} \mathrm{C}$, $20 \%, 13 \mathrm{hPa}, 2 \mathrm{~m} / \mathrm{s}$. A Tabela 3 apresenta a média temporal do EQM calculado para essas variáveis em cada mês e o desvio padrão em relação a essa média. Essa norma do erro é bastante
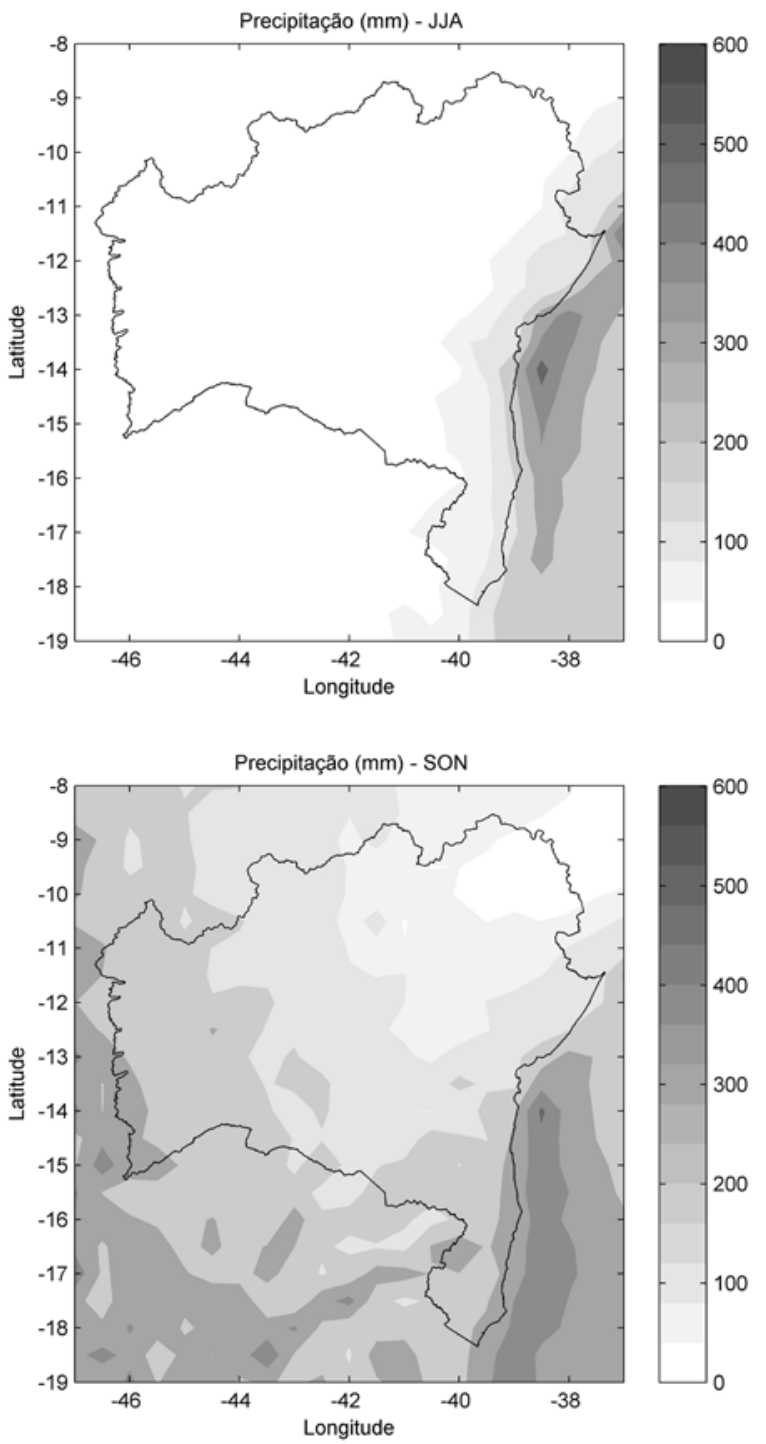

severa para os modelos atmosféricos, pois mesmo que o padrão de larga escala esteja bem simulado, um pequeno deslocamento do padrão do modelo em relação às observações provoca grandes erros, principalmente em regiões de forte gradiente.

Os EAMs calculados em relação às 29 estações do INMET estão apresentados na Tabela 4. O maior erro da precipitação foi verificado no centro do Estado na estação de Lençóis, atingindo $69 \mathrm{~mm} / \mathrm{mês}$, seguido pelos erros de estações próximas do litoral. Em grande parte do Estado, os EAMs da precipitação foram negativos, entre 0 e $-30 \mathrm{~mm} / \mathrm{mês}$. Os maiores erros de temperatura, umidade relativa e pressão de superficie foram verificados na estação de Morro do Chapéu. Esses erros foram causados principalmente pelas grandes diferenças entre a topografia do modelo e a real. Em Morro do Chapéu, a altitude da estação é de 1003 m e a do modelo é de apenas 521 m. Os EAMs
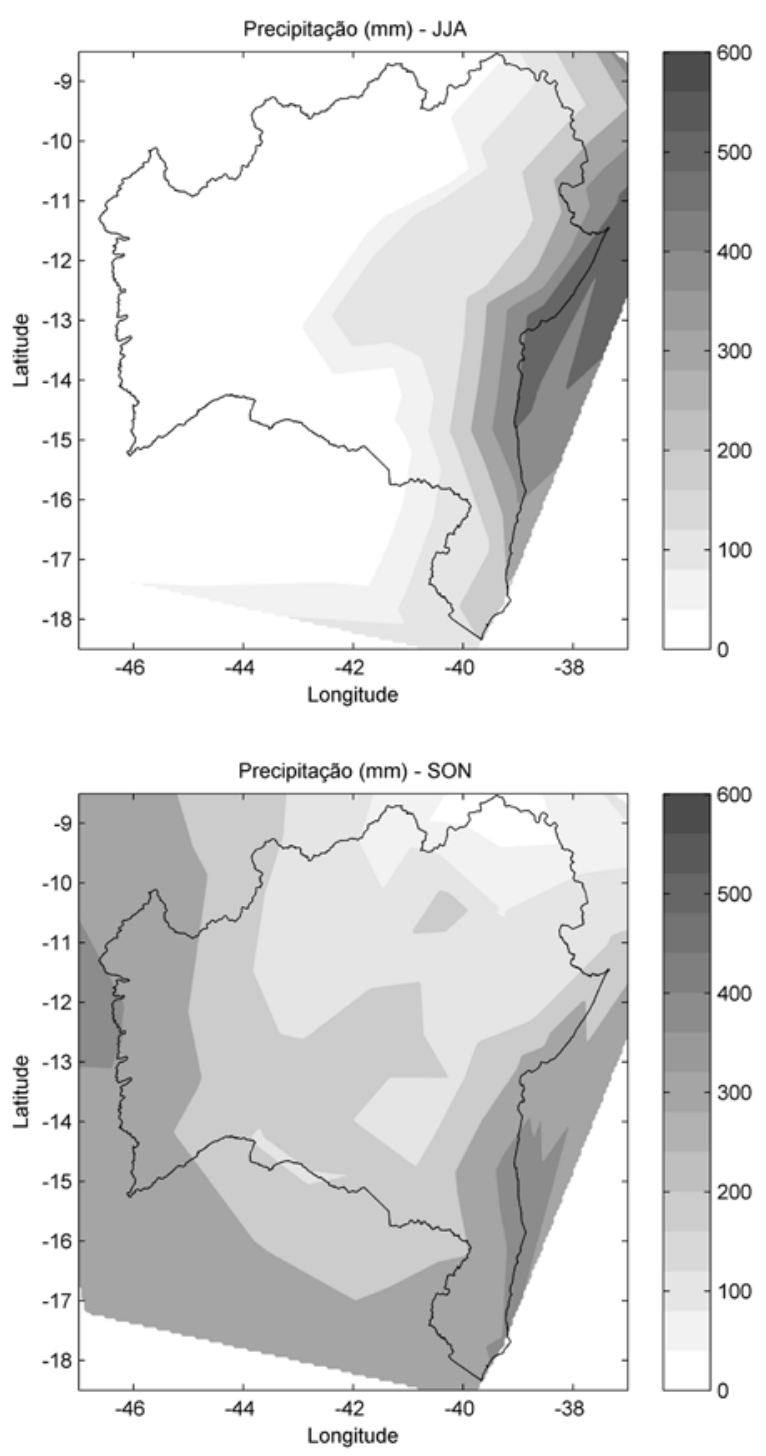

Figura 4 - Precipitação sazonal climatológica (mm) de acordo com o HadRM3P (coluna da esquerda) e dados observados do INMET (coluna da direita) para os meses de junho-julho-agosto em (a) e (b); e setembro-outubro-novembro em (c) e (d). 
foram de 3,4 ${ }^{\circ} \mathrm{C},-10,51 \%$ e 33 hPa nessa estação. Sem considerar Morro do Chapéu, todo o Estado da Bahia teve sua temperatura média bem simulada com EAM em grande parte entre $\pm 1^{\circ} \mathrm{C}$.

Além de Morro do Chapéu, o modelo subestimou a umidade relativa em mais de 5\% em Lençóis e Serrinha. O modelo super-estimou a umidade em mais de 5\% em Cipó no nordeste do Estado e Remanso no extremo oeste. Sem considerar as estações citadas acima, os EAMs da umidade ficaram entre $-4 \%$ e $2 \%$. Para a pressão de superfície, os menores EAMs ficaram no leste do Estado entre - 10 e $10 \mathrm{hPa}$, e os maiores EAMs

Tabela 3 - Valor médio e desvio padrão do EQM.

\begin{tabular}{cccccc}
\hline & $\begin{array}{c}\text { Temp. } \\
{\left[{ }^{\circ} \mathrm{C}\right]}\end{array}$ & $\begin{array}{c}\text { Um. Rel. } \\
{[\%]}\end{array}$ & $\begin{array}{c}\text { Pres. Sup. } \\
{[\mathrm{hPa}]}\end{array}$ & $\begin{array}{c}\text { Int. Vento } \\
{[\mathrm{m} / \mathrm{s}]}\end{array}$ & $\begin{array}{c}\text { Precip. } \\
{[\mathrm{mm}]}\end{array}$ \\
\hline \multirow{2}{*}{ Média } & 1,20 & 7,66 & 10,9 & 1,08 & 64,4 \\
\multirow{2}{*}{ Desvio padrão } & 0,39 & 3,01 & 2,5 & 0,32 & 38,6 \\
\hline
\end{tabular}
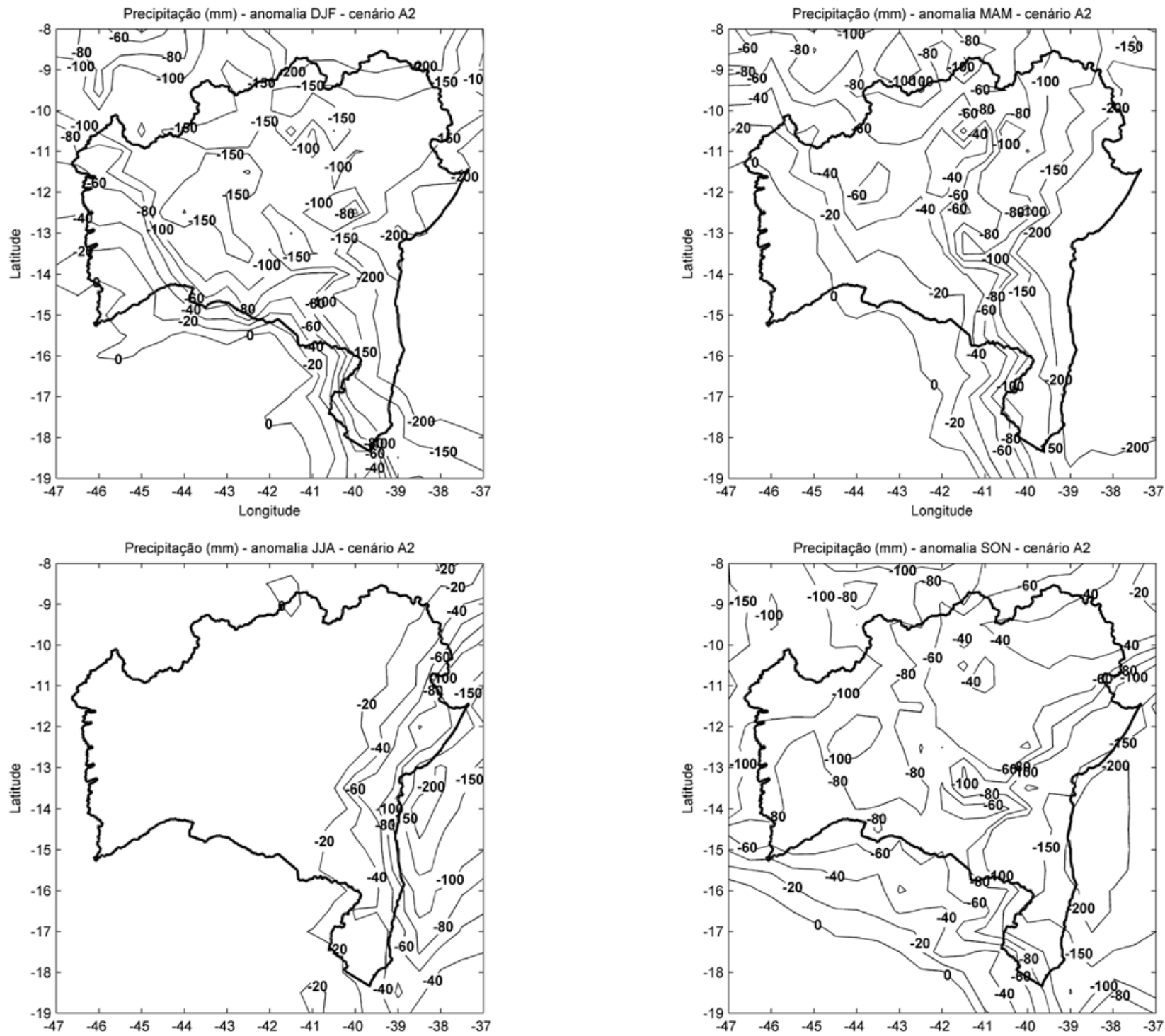

Figura 5 - Anomalia de precipitação sazonal acumulada do cenário A2 em relação ao clima presente (A2 menos clima presente) para (a) DJF; (b) MAM; (c) JJA e (d) SON. Unidade em mm. 
em regiões da Chapada Diamantina, como Morro do Chapeú e Vitória da Conquista no sudoeste do Estado. Esses erros estão associados às substanciais diferenças entre a topografia do modelo e a real. Em relação à intensidade dos ventos, os maiores erros foram observados ao redor de Salvador, onde o modelo superestimou a intensidade em aproximadamente 1,5 m/s.

\subsection{Comparação dos Cenários A2 e B2 com a Simulação do Clima Presente}

Considerando as simulações do HadRM3P para os cenários A2 e B2 no período de 2070 a 2100, observam-se mudanças substanciais na média e na variabilidade das variáveis analisadas. As diferenças entre as simulações dos cenários futuros e do clima presente para a precipitação, temperatura a $2 \mathrm{~m}$, umidade relativa a $2 \mathrm{~m}$, pressão de superfície e intensidade dos ventos foram investigadas, mas serão apresentados os resultados apenas para a precipitação e a temperatura a $2 \mathrm{~m}$.

Os padrões espaciais das diferenças entre A2 e clima presente, e entre B2 e clima presente para as variáveis mencionadas acima foram muito parecidos, mas as magnitudes produzidas pelo cenário A2 foram maiores do que para o B2, como esperado. Por isso, nesse trabalho serão apresentados alguns resultados associados às diferenças entre o cenário A2 e o clima presente e comentários sobre as diferenças com o B2.

Considerando a sazonalidade da precipitação, a Figura 5 apresenta a diferença de precipitação sazonal média sobre o Estado da Bahia para DJF, MAM, JJA e SON entre o A2 e o

Tabela 4 - Valor médio do EAM por estação do INMET.

\begin{tabular}{|c|c|c|c|c|c|c|c|}
\hline N. & Estação & $\begin{array}{c}\text { Temperatura } \\
{\left[{ }^{\circ} \mathrm{C}\right]}\end{array}$ & $\begin{array}{c}\text { Umidade } \\
{[\%]}\end{array}$ & $\begin{array}{c}\text { Pressão } \\
{[\mathrm{kPa}]}\end{array}$ & $\begin{array}{l}\text { Vento } \\
{[\mathrm{m} / \mathrm{s}]}\end{array}$ & $\begin{array}{r}\text { Precipita } \\
\text { mensal }\end{array}$ & $\begin{array}{l}\text { [mm] } \\
\text { anual }\end{array}$ \\
\hline 1 & Itiruçu & 1,29 & $-3,85$ & 1,83 & 0,52 & 8,0 & 96 \\
\hline 2 & Ituaçu & $-0,33$ & 2,02 & $-0,46$ & 1,58 & $-4,4$ & -52 \\
\hline 3 & Jacobina & $-0,44$ & $-0,75$ & $-1,33$ & 0,28 & $-29,7$ & -356 \\
\hline 4 & Lençóis & $-0,86$ & $-7,43$ & $-3,62$ & 1,70 & $-69,5$ & -834 \\
\hline 5 & Monte Santo & 0,70 & $-0,87$ & 0,38 & 1,03 & $-17,3$ & -208 \\
\hline 6 & Morro do Chapéu & 3,40 & $-10,51$ & 3,30 & 0,00 & $-19,3$ & -231 \\
\hline 7 & Paulo Afonso & $-0,26$ & 0,74 & $-0,81$ & 0,74 & $-7,8$ & -94 \\
\hline 8 & Remanso & $-1,16$ & 10,07 & 0,80 & 1,39 & $-15,0$ & -180 \\
\hline 9 & Salvador & 0,71 & $-1,12$ & 0,54 & 2,12 & $-55,9$ & -670 \\
\hline 10 & Santa Rita de Cássia & 0,63 & 0,21 & $-0,32$ & 0,95 & $-23,5$ & -282 \\
\hline 11 & Senhor do Bonfim & 0,97 & $-3,26$ & 0,89 & 0,62 & $-33,6$ & -404 \\
\hline 12 & Serrinha & 1,09 & $-6,80$ & $-0,59$ & 1,03 & $-13,8$ & -165 \\
\hline 13 & Vitória da Conquista & 1,43 & 1,58 & 2,57 & $-0,45$ & 8,9 & 107 \\
\hline 14 & Alagoinhas & $-0,01$ & 2,52 & $-0,14$ & 1,34 & $-28,5$ & -343 \\
\hline 15 & Barra & 0,05 & $-0,22$ & $-0,73$ & 0,11 & 8,9 & 107 \\
\hline 16 & Barreiras & $-0,30$ & $-4,70$ & $-2,07$ & 0,37 & $-28,6$ & -343 \\
\hline 17 & Bom Jesus da Lapa & 0,24 & $-0,28$ & $-0,46$ & 0,49 & $-5,5$ & -65 \\
\hline 18 & Caetité & 1,12 & 1,31 & 1,55 & $-1,15$ & $-3,3$ & -40 \\
\hline 19 & Camaçari & 0,78 & $-0,78$ & $-0,10$ & 1,52 & $-54,1$ & -650 \\
\hline 20 & Canavieiras & 0,83 & $-1,23$ & $-0,33$ & 0,63 & $-3,3$ & -40 \\
\hline 21 & Caravelas & 0,31 & 1,23 & $-0,23$ & 0,09 & 8,4 & 101 \\
\hline 22 & Cipó & $-0,88$ & 9,23 & $-0,87$ & $-0,30$ & $-52,1$ & -625 \\
\hline 23 & Correntina & $-0,35$ & $-4,01$ & $-0,67$ & $-0,16$ & $-28,5$ & -342 \\
\hline 24 & Cruz das Almas & 0,46 & 0,12 & $-0,85$ & 0,48 & $-20,1$ & -241 \\
\hline 25 & Feira de Santana & 0,24 & 2,08 & $-1,39$ & 0,29 & $-29,2$ & -351 \\
\hline 26 & Guaratinga & $-0,13$ & 3,41 & 0,57 & $-0,13$ & $-8,1$ & -97 \\
\hline 27 & Théus & 0,65 & $-2,22$ & $-0,03$ & 1,05 & $-45,9$ & -551 \\
\hline 28 & Irecê & 0,69 & 0,66 & 0,31 & $-0,57$ & $-7,8$ & -94 \\
\hline 29 & Itaberaba & 0,22 & $-1,41$ & $-1,15$ & 1,14 & $-34,4$ & -412 \\
\hline
\end{tabular}


clima presente. Houve redução de precipitação em todo o Estado para todas as estações do ano em ambos os cenários A2 e B2. Em DJF, as maiores reduções - entre 150 e 200 mm no trimestre foram verificadas ao longo do litoral e em diversas subregiões do semi-árido. As menores anomalias foram produzidas no extremo sudoeste do Estado próximo ao Sudeste do Brasil, região na qual houve um aumento de precipitação do A2 e do B2 em relação ao clima presente. Em MAM, as maiores reduções - da ordem de $300 \mathrm{~mm}$ - ocorreram no litoral. É nessa estação que acontece o pico da precipitação no Estado verificado no litoral. A magnitude das anomalias decresceu progressivamente do litoral em direção ao interior do Estado para oeste, até atingir valores próximos a zero no extremo oeste e sudoeste do Estado. Para o cenário B2, um padrão semelhante foi encontrado, com as maiores anomalias no litoral também ao redor de 300 mm mas com um gradiente mais suave de redução da magnitude das anomalias em direção ao interior do Estado. Em JJA, a precipitação no A2 e B2 são muito baixas em grande parte do Estado, isto é, foi mantida a sazonalidade observada no clima presente. As anomalias registradas foram menores que $20 \mathrm{~mm}$ em quase todo o Estado, exceto numa faixa próxima ao litoral, onde houve redução de até $150 \mathrm{~mm}$, tanto para o cenário A2 como para o B2. Para SON, as maiores reduções no cenário A2 foram também no litoral - em mais de 150 mm - e as menores reduções foram verificadas no nordeste do Estado, região que climatologicamente é contemplada com baixas precipitações nessa época do ano (Figura 4). Para o cenário B2, as anomalias em SON foram muito parecidas com as do A2. A única diferença
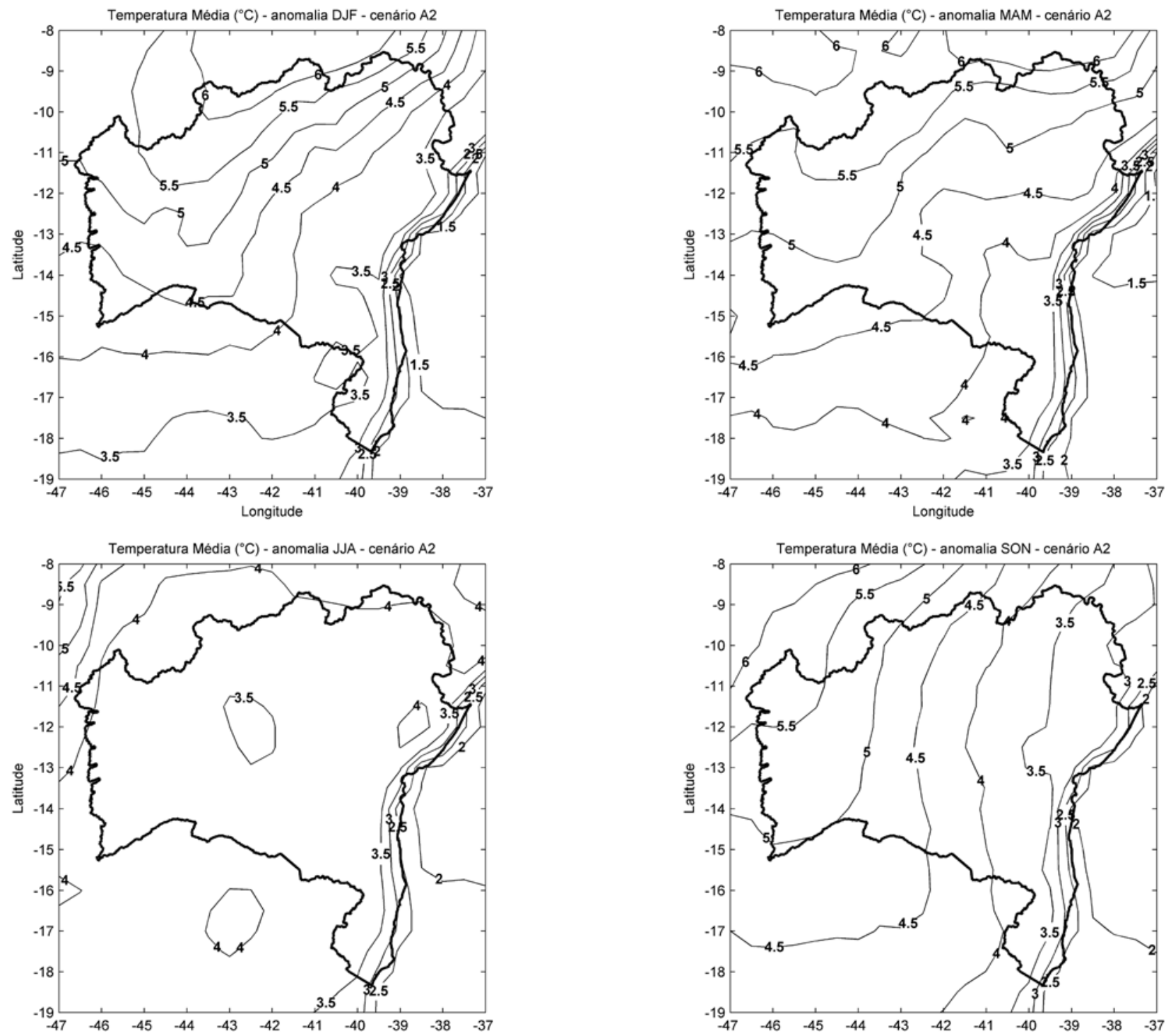

Figura 6 - Anomalia de temperatura média sazonal do cenário A2 em relação ao clima presente (A2 menos clima presente) para (a) DJF; (b) MAM; (c) JJA e (d) SON. Unidade em oC. 
significativa foi que no cenário B2 houve uma maior redução de precipitação no sudoeste do Estado. Enquanto o cenário A2 produziu redução entre 80 e 100 mm, o B2 produziu reduções maiores do que $100 \mathrm{~mm}$. Em resumo, pode ser observado que o ciclo anual de precipitação sobre as diversas regiões do Estado foi mantido, mas com magnitudes menores, principalmente em DJF e MAM ao longo do litoral.

Considerando as reduções de precipitação acumulada no ano (não mostrado), as maiores anomalias foram de aproximadamente $900 \mathrm{~mm}$ localizadas ao longo do litoral nos cenários A2 e B2, sendo que na região oceânica ao largo da costa da Bahia próximo de Salvador as diferenças foram de até 1500 mm/ano. As menores reduções de $150 \mathrm{~mm} / \mathrm{ano}$ foram produzidas no sudoeste do Estado para os dois cenários. Considerando valores percentuais da precipitação anual no cenários A2 em relação à simulação do clima presente, houve uma redução no litoral de $70 \%$, sendo que no litoral norte atingiu $80 \%$, no sudoeste do Estado de 10\% e no vale do Rio São Francisco entre 20 e $60 \%$. Para o cenário B2, os valores foram semelhantes, sendo que no litoral a redução foi de até $70 \%$, no sudoeste de $10 \%$ e no vale do Rio São Francisco entre 20 e 50\%.

Anomalias positivas de temperatura a $2 \mathrm{~m}$ foram registradas em todo o Estado ao longo do ano para os cenários A2 e B2, mas com as anomalias do A2 maiores do que as do B2 entre 1 e 1,5 ${ }^{\circ} \mathrm{C}$. Em DJF, o cenário A2 produziu anomalias máximas entre 5,5 e $6^{\circ} \mathrm{C}$ no noroeste e norte do Estado, como mostrado da Figura 6a. As menores anomalias foram de $20 \mathrm{C}$ ao longo da linha costeira. Na maior parte do Estado as anomalias ficaram entre 3,5 e $5,5^{\circ} \mathrm{C}$. Para o B2, as maiores anomalias foram de $4,5^{\circ} \mathrm{C}$ a oeste do Lago de Sobradinho e na maior parte do Estado elas ficaram entre 2,5 e $4^{\circ} \mathrm{C}$. Em MAM, o padrão de anomalia de temperatura foi semelhante a DJF, mas com um aumento de temperatura maior em toda a região leste do Estado. Particularmente, observa-se um deslocamento da isotermas de 4 e $4,5^{\circ} \mathrm{C}$ para oeste. No cenário B2 para MAM, o padrão foi o mesmo da Figura 6b, mas com valores $1^{\circ} \mathrm{C}$ menores. Para JJA, mostrado na Figura 6c, o acréscimo de temperatura foi bastante homogêneo na maior parte do Estado, permanecendo entre 3,5 e $4^{\circ} \mathrm{C}$. No litoral, as anomalias ficaram entre 2,5 e $3,5^{\circ} \mathrm{C}$. No cenário B2, o mesmo padrão foi produzido com valores novamente cerca de $1^{\circ} \mathrm{C}$ menores. Em SON, as anomalias do cenário $\mathrm{A} 2$ produziram um padrão com isotermas na direção meridional com valores entre 2 e $2,5^{\circ} \mathrm{C}$ no litoral, progressivamente aumentando para oeste até $5,5^{\circ} \mathrm{C}$ no extermo oeste do Estado. Para o B2, a distribuição espacial das anomalias foi muito semelhante com valores cerca de $1^{\circ} \mathrm{C}$ menores.

Considerando as diferenças das médias anuais de temperatura a $2 \mathrm{~m}$ em relação ao clima presente (não mostrado), anomalias positivas maiores que $3,5^{\circ} \mathrm{C}$ e $2,5^{\circ} \mathrm{C}$ foram produzidas em quase todo o Estado nos cenários A2 e B2, respectivamente, exceto na região litorânea onde as anomalias foram entre $2 \mathrm{e}$ $3,5^{\circ} \mathrm{C}$ para o $\mathrm{A} 2$ e entre 1,5 e $2,5^{\circ} \mathrm{C}$ para o $\mathrm{B} 2$.

\section{CONCLUSÕES}

O modelo HadRM3P reproduziu com acurácia a distribuição espacial da média anual e do ciclo sazonal de precipitação e da temperatura do ar a $2 \mathrm{~m}$ sobre o Estado da Bahia. Entretanto, algumas discrepâncias em relação à climatologia foi observada, como esperado para qualquer modelo numérico. O HadRM3P não conseguiu produzir as magnitudes máximas de precipitação observada no oeste do Estado em DJF e na faixa litorânea em MAM. Em JJA, ele não simulou nenhuma chuva no oeste da Bahia e no semi-árido, além de subestimar a precipitação no litoral. Em SON, o modelo produziu menor precipitação do que o observado no nordeste do Estado. Em relação à temperatura a $2 \mathrm{~m}$, o modelo simulou valores em DFJ e MAM menores que as observações, de 1 a $2^{\circ} \mathrm{C}$, e em JJA e SON, simulou valores maiores, de 1 a $3^{\circ} \mathrm{C}$. O erro absoluto médio anual da temperatura a $2 \mathrm{~m}$ ficou entre -1 e $1^{\circ} \mathrm{C}$ na maior parte do Estado.

De forma geral, a avaliação objetiva do modelo em relação aos dados observados sobre o período 1960-1990, indicou que as magnitudes dos erros quadráticos médios e dos erros absolutos médios de temperatura a $2 \mathrm{~m}$, umidade relativa a $2 \mathrm{~m}$, pressão de superfície e intensidade do vento de superfície foram relativamente pequenas. Os erros da precipitação foram maiores com tendência de subestimativa. Entretanto, esses erros não desqualificam o modelo para ser usado em experimentos numéricos para investigação climática, visto que a simulação e a previsão acurada da distribuição e magnitude da precipitação é ainda hoje uma real limitação dos modelos atmosféricos.

Os maiores erros da temperatura a $2 \mathrm{~m}$ e pressão de superfície foram causados principalmente pelas grandes diferenças de altitude entre a topografia do modelo e a topografia real. Por exemplo, em Morro do Chapéu e Vitória da Conquista, as altitudes das estações são 1003 m e 875 m, respectivamente, enquanto as altitudes do modelo nesses pontos são 521 m e 523 $\mathrm{m}$, respectivamente. Essas diferenças podem causar impacto na umidade relativa e na distribuição espacial das chuvas. Devido à importância da topografia como forçante de meso-escala e considerando a disponibilidade de bases cartográficas digitais de alta resolução, recomenda-se que um esforço maior seja dedicado à elaboração de uma topografia do modelo mais precisa antes da realização de longas integrações climáticas.

A comparação dos resultados do HadRM3P sob os cenários A2 e B2 com a simulação do clima presente, indicou que houve redução de precipitação e aumento da temperatura a $2 \mathrm{~m}$ em todo o Estado da Bahia. O mesmo padrão espacial de modificação da temperatura a $2 \mathrm{~m}$ e da precipitação foi 
produzido para os dois cenários. mas com maiores magnitudes para o A2. A maior redução de precipitação anual foi observada no litoral (cerca de 70\%) tanto para o A2 como para o B2, e o maior aumento de temperatura foi no noroeste e norte (cerca de $5^{\circ} \mathrm{C}$ para o $\mathrm{A} 2$ e $4^{\circ} \mathrm{C}$ para o B2). O semi-árido sofreu reduções de precipitação anual entre 20 e $60 \%$ no cenário A2 e entre 20 e 50\% no cenário B2. Os maiores aumentos de temperatura do ar foram produzidos no noroeste e norte do Estado em aproximadamente $5,5^{\circ} \mathrm{C}$ para o $\mathrm{A} 2$ e $4,5^{\circ} \mathrm{C}$ para o $\mathrm{B} 2$. No litoral, os aumentos ficaram entre 2 e $3,5^{\circ} \mathrm{C}$ para o $\mathrm{A} 2$ e entre 1,5 e $2,5^{\circ} \mathrm{C}$ para o $\mathrm{B} 2$.

No caso da simulação hidrológica, normalmente são utilizados forçantes atmosféricos observados, principalmente campos de temperatura de superfície e precipitação. Para estudos de impactos de cenários de mudanças climáticas no ciclo hidrológico de bacias hidrográficas, geralmente não são utilizados os campos produzidos diretamente pelos modelos climáticos (e.g., Xu et al., 2005). Há várias metodologias de “dowscaling” sendo hoje investigadas para essa adaptação (e.g. Fowler et al. 2007) e isso será abordado na próxima etapa do presente projeto.

Assim, a principal característica que se busca no modelo climático para simulação hidrológica é a sua capacidade de produzir uma variabilidade sazonal e interanual de boa qualidade, e ser sensível às alterações nas condições de contorno de superfície e de composição química da atmosfera. Como os ciclos sazonais da precipitação e das outras variáveis atmosféricas na superfície foram bem reproduzidos pelo HadRM3P sobre o Estado da Bahia, pode-se considerar esse modelo como uma boa opção para avançar na investigação dos efeitos das mudanças climáticas sobre os recursos hídricos na região.

\section{AGRADECIMENTOS}

Os autores agradecem ao CNPq pelos recursos disponibilizados através do projeto de pesquisa "Mudanças Climáticas e Recursos Hídricos na Bahia” (processo 473871/2007-6), e pelas bolsas de pesquisa CNPq/CT-Energ e $\mathrm{CNPq} / \mathrm{PQ}$. Agradecem ao Dr. José Marengo e ao Sr. Daniel Caetano Santos do CPTEC/INPE pela disponibilização dos dados do modelo regional HadRM3P e pela parceria e acolhimento em Cachoeira Paulista/SP. Ao Dr. Divino Moura e Comandante Alaor D'All Antonia Jr. do INMET pela disponibilização dos dados in situ observados na Bahia.

\section{REFERÊNCIAS BIBLIOGRÁFICAS}

AMBRIZZI, T.; ROCHA, R.P.; MARENGO, J.A.; PISNITCHENCO, I.; NUNES, L.A.; FERNANDEZ, J.P.R. Cenários regionalizados de clima no Brasil e América do Sul para o Século XXI: Projeções de clima futuro usando três modelos regionais. Relatório 3. CPTEC/INPE; IAG/ USP; FBDS. Ministério do Meio Ambiente. Secretaria de Biodiversidade e Florestas. Diretoria de Conservação da Biodiversidade. 108 pp, 2007.

CHAVES, R.R. Variabilidade da precipitação na região sul do Nordeste do Brasil e sua associação com padrões atmosféricos. Tese de M.Sc. São José dos Campos, INPE, 159 p., 1999. CHAVES, R.R.; CAVALCANTI, I.F.A. Atmospheric circulation features associated with rainfall variability over southern Northeast Brazil. Mon. Wea. Rev., 129, 2614-2626, 2001.

CHAVES, R.R.; NOBRE, P. Interactions between the sea surface temperature over the South Atlantic Ocean and the South Atlantic Convergence Zone. Geophysical Research Letters, 31, L03204, 2004.

CHAVES, R.R.; COLLINS, J; SILVA MARQUES, V. Summertime temperature variability in South America between 1948-2007. CLIVAR Exchanges, 13, 19-20, 2008. COLLISCHONN, W.; TUCCI, C.E.M. Simulação hidrológica de grandes bacias. Revista Brasileira de Recursos Hídricos, 6, 95-118, 2001.

EMANUEL, K. Increasing destructiveness of tropical cyclones over the past 30 years. Nature, 436, 686-688, 2005.

FOWLER, H.J.; BLENKINSOP, S.; TEBALDI, C. Linking climate change modelling to impact studies: recent advances in dowscaling techniques for hydrological modelling. International Journal of Climatology, 27: 1547-1578, 2007. IPCC. Climate Change 2001: The Scientific Basis. Contribution of Working Group I to the Third Assessment Report of the Intergovernmental Panel on Climate Change [Houghton, J.T., et al. (eds.)]. Cambridge University Press, Cambridge, United Kingdom and New York, NY, USA, 881 pp, 2001.

IPCC. Climate Change 2007 - The Physical Science Basis Contribution of Working Group I to the Fourth Assessment Report of the Intergovernmental Panel on Climate Change [Solomon, S, Qin, M. Manning, Z. Chen, M. Marquis, K.B. Averyt, M. Tignor and H.L. Miller (eds.)]. Cambridge University Press, Cambridge, United Kingdom and New York, NY, USA, 996 pp, 2007.

JOHNS, T.C.; GREGORY, J.M.; INGRAM, W.J.; JOHNSON, C.E.; JONES, A.; LOWE, J.A.; MITCHELL, J.F.B.; ROBERTS, D.L.; SEXTON, D.M.H.; STEVENSON, D.S.; TETT, S.F.B.; WOODAGE, M.J., 2003: Anthropogenic climate change for 1860 to 2100 simulated with the HadCM3 model under updated emissions scenarios. Climate Dynamics., 20, 583-612, 2003.

KOUSKY, V. E.; CHU, P. S. Flutuations in annual rainfall for northeast Brazil. Journal Meteorological Society Japan, 56, 457-465, 1978.

KOUSKY, V. E. Frontal influences on Northeast Brazil. Monthly Weather on Review, 107, 1140-1153, 1979. 
KOUSKY, V. E. Diurnal rainfall variation in Northeast Brazil. Monthly Weather Review, 108, 488-498, 1980.

KOUSKY, V.E.; ROPELEWSKI, C.H. Extremes in the Southern Oscillation and their relationship to precipitation anomalies with emphasis on the South American region. Revista Brasileira de Meteorologia, 4, 351-363, 1989.

MARENGO, J.A. Mudanças climáticas globais e regionais: avaliação do clima atual do Brasil e projeções de cenários climáticos do futuro. Revista Brasileira de Meteorologia, 16, 1-18, 2001.

MARENGO, J.A.; VALVERDE, M.C. Caracterização do clima no século XX e cenários de mudanças de clima para o Brasil no século XXI usando os modelos do IPCC AR4. 20 p. INPE ePrint: sid.inpe.br/mtc-m17@80/2007/04.19.18.09v1,2007.

MARENGO, J.A.; NOBRE, C.A.; SALATI, E.; AMBRIZZI, T. Caracterização do clima atual e definição das alterações climáticas para o território brasileiro ao longo do Século XXI. Sumário Técnico. CPTEC/INPE; IAG/USP; FBDS. Ministério do Meio Ambiente. Secretaria de Biodiversidade e Florestas. Diretoria de Conservação da Biodiversidade. 54 p, 2007.

MOLION, L.C.B.; BERNARDO, S.O.Uma revisão da dinâmica das chuvas no Nordeste brasileiro. Revista Brasileira de Meteorologia, 17, 1-10, 2002.

NAKICENOVIC N.; SWART, R.J. Emissions Scenarios 2000 - Special Report of the Intergovernmental Panel on Climate Change, Cambridge University Press, Cambridge, 570 p, 2000.

NOBRE, C. A.; MOLION, L. C. B. The Climatology of drought and drought prediction. The Impact of Variations on Agriculture, 2, 305-323, 1988.
NOGUÉS-PAEGLE, J.; MO, K.C. Alternating wet and dry conditions over South America during summer. Mon. Wea. Rev., 125, 279-291, 1997.

POPE, V.D.; GALLANI, M.L.; ROWNTREE, P.R.; STRATTON, R.A. The impact of new physical parametrizations in the Hadley Centre climate model: HadAM3. Clim Dyn 16: 123-146, 2000.

PRECIS. Providing Regional Climates for Impacts Studies. The Hadley Centre Regional Climate Modelling system. Hadley Centre, Exeter, UK. 29 pp, 2002.

RAO, V. B.; HADA, K. Characteristics of rainfall over Brazil: annual variations and connections with the southern oscillation. Theoretical and Applied Climatology, 42, 8191, 1990.

RAO, V. B.; LIMA, M. C.; FRANCHITO, S. H. Seasonal and interanual variations of rainfall over eastern Northeast Brazil. Journal of Climatology,.6, 1754-1763, 1993.

SOUZA, E.; NOBRE, P. Uma revisão sobre o padrão de dipolo do Oceano Atlântico tropical, Revista Brasileira de Meteorologia, 13, 31-44, 1998.

XU, C.Y.; WIDEN, E.; HALLDIN, S. Modelling hydrological consequences of climate change-progress and challenges. Advances in Atmospheric Sciences, 22, 789-797, 2005.

YAMAZAKI, Y.; RAO, V.B. Tropical cloudiness over South Atlantic ocean. J. Meteorolo. Soc. Japan, 55, 205-207, 1977. 